\title{
Diagnostic journey and impact of enzyme replacement therapy for mucopolysaccharidosis IVA: a sibling control study
}

Can Ficicioglu* ${ }^{*}$, Dena R. Matalon², Nicole Luongo ${ }^{1}$, Caitlin Menello ${ }^{1}$, Tracy Kornafel ${ }^{1}$ and Andrew J. Degnan ${ }^{3}$

\begin{abstract}
Background: Mucopolysaccharidosis (MPS) IVA, also known as Morquio A syndrome, is a rare autosomal recessive lysosomal storage disorder caused by a deficiency in the enzyme N-acetylgalactosamine-6-sulfatase. Early recognition, diagnosis, and treatment of this progressive, multisystem disease by enzyme replacement therapy (ERT) can lead to improved outcomes and reduced mortality.

Methods: This report documents the diagnostic journey and treatment with ERT of three siblings with MPS IVA. Clinical outcome measures included growth, endurance, imaging, cardiac, respiratory, ophthalmology, and laboratory evaluations.

Results: Three siblings, diagnosed at 14.7, 10.1, and 3.2 years of age, demonstrated clinical improvement with weekly infusions of $2.0 \mathrm{mg} / \mathrm{kg}$ elosulfase alfa (Vimizim ${ }^{\circledR}$, BioMarin Pharmaceutical, Novato, CA, USA). Patient 1 (oldest sibling) and Patient 2 (middle sibling) experienced a diagnostic delay of 8 years 7 months and 4 years after symptom onset, respectively. All three patients demonstrated improvements in growth, 6-min walk distance, joint range of motion, and respiratory function after 30 months of ERT. The treatment was well tolerated without any adverse events.

Conclusions: This case series highlights the importance of early recognition of the clinical and imaging findings that are initially subtle in MPS IVA. Early treatment with ERT is necessary to slow irreversible disease progression and improve patient outcomes. The oldest sibling experienced improvements in mobility despite severe symptoms resulting from a late diagnosis. When evaluating patients with skeletal anomalies, imaging multiple body regions is recommended. When findings such as anterior beaking of vertebrae or bilateral femoral head dysplasia are present, MPS IVA should be included in the differential diagnosis. Newborn screening must be considered for early detection, accurate diagnosis, and initiation of treatment to reduce morbidity.
\end{abstract}

Keywords: Mucopolysaccharidosis IVA, Enzyme replacement therapy, Anterior beaking, Platyspondyly, Diagnosis, Treatment

*Correspondence: ficicioglu@email.chop.edu

1 Division of Human Genetics/Metabolism, Lysosomal Storage Diseases Program, The Children's Hospital of Philadelphia, Perelman School of Medicine, The University of Pennsylvania, 3401 Civic Center Blvd., Philadelphia, PA 19104, USA

Full list of author information is available at the end of the article

\section{Background}

Mucopolysaccharidosis (MPS) IVA, also referred to as Morquio A syndrome, is a rare autosomal recessive lysosomal storage disorder caused by a deficiency in the enzyme N-acetylgalactosamine-6-sulfatase (GALNS) [1-4]. Impaired degradation of the glycosaminoglycans (GAGs) keratan sulfate and chondroitin 6-sulfate stemming from reduced GALNS activity results in undegraded GAGs in lysosomes across multiple tissues and

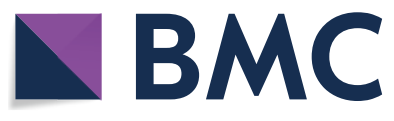

(c) The Author(s) 2020. Open Access This article is licensed under a Creative Commons Attribution 4.0 International License, which permits use, sharing, adaptation, distribution and reproduction in any medium or format, as long as you give appropriate credit to the original author(s) and the source, provide a link to the Creative Commons licence, and indicate if changes were made. The images or other third party material in this article are included in the article's Creative Commons licence, unless indicated otherwise in a credit line to the material. If material is not included in the article's Creative Commons licence and your intended use is not permitted by statutory regulation or exceeds the permitted use, you will need to obtain permission directly from the copyright holder. To view a copy of this licence, visit http://creativecommons.org/licenses/by/4.0/. The Creative Commons Public Domain Dedication waiver (http://creativeco mmons.org/publicdomain/zero/1.0/) applies to the data made available in this article, unless otherwise stated in a credit line to the data. 
organs, particularly in chondrocytes [3]. MPS IVA typically presents with bony abnormalities, short stature, and skeletal dysplasia $[3,5,6]$. Other findings include respiratory insufficiency, cardiovascular abnormalities, and dental impacts $[5,7]$. Due to the progressive and heterogeneous nature of the disease and its variable presentation, early diagnosis can be challenging $[1,8]$. However, prompt recognition, accurate diagnosis, and proper management of the disorder are necessary to improve patient outcomes [8].

Prior to the approval of elosulfase alfa $\left(\right.$ Vimizim $^{\circledR}$, BioMarin Pharmaceutical, Novato, CA, USA) as an enzyme replacement therapy (ERT) for patients with MPS IVA $[9,10]$, the treatment of MPS IVA mainly consisted of supportive therapy [11]. In a randomized, double-blind, placebo-controlled phase 3 pivotal trial that included patients $\geq 5$ years of age, treatment with elosulfase alfa was well tolerated and resulted in a considerable improvement in endurance (6-min walk distance [6MWD]), substantial reduction in urinary keratan sulfate, and improvements in pulmonary function, height, and growth compared with placebo [11]. In a phase 2, open-label study in patients younger than 5 years of age, elosulfase alfa was well tolerated and resulted in a reduction of urinary keratan sulfate and a trend toward improvement in growth [12]. Previously published case reports of siblings with MPS disorders have shown that earlier treatment and management of these disorders results in improved outcomes [13-15].

Evidence of the impact of treatment with ERT and other interventions is needed to help inform healthcare providers of the importance of early diagnosis and to support newborn screening initiatives. In this case report, we describe three African American siblings who presented with similar symptoms at 5, 5, and 3 years of age, respectively. The two older siblings experienced a delay in diagnosis after the onset of symptoms, while the youngest sibling was suspected to have the same condition. The diagnosis for all three siblings was confirmed as MPS IVA via molecular genetic analysis and biochemical data.
The differences in the siblings' clinical courses highlight the importance of early recognition of MPS IVA because of the progressive nature of this disorder; specifically, understanding and recognizing the skeletal abnormalities of MPS IVA early will enable timelier diagnosis and treatment, which could help reduce mortality and morbidity.

\section{Methods}

The three siblings with MPS IVA presented at Children's Hospital of Philadelphia (CHOP) in the United States for clinical care. The siblings were born to non-consanguineous parents. Parental consent was obtained from both parents to use the patients' medical data and photographs. All radiographs, magnetic resonance imaging (MRI), genetic testing, and other results were performed clinically and reviewed. All three patients initiated ERT (elosulfase alfa, BioMarin Pharmaceutical Inc., Novato, CA, USA) at the same time (Patient 1, 14.7 years of age; Patient 2, 10.1 years of age; Patient 3, 3.2 years of age).

\section{Results}

Clinical manifestations and laboratory evaluations

The clinical course of the three siblings is summarized in Table 1. All patients presented with similar symptoms at different ages. Patient 1 (oldest sibling) was noted to have a limp and endorsed hip pain at 5 years of age; he was diagnosed with bilateral LeggCalve-Perthes disease (Fig. 1). At 7 years of age, he was referred to orthopedics for further evaluation and treatment at Children's Hospital of Philadelphia (CHOP). Upon examination at the clinic, he presented with an abnormal wide gait with the lower legs placed in valgus; tenderness on the bilateral greater trochanter; and full range of motion, but with mild tenderness, on both knees and ankles. He underwent hip surgery and experienced a prolonged recovery with worsening of his symptoms. After his recovery, he was lost to follow-up and was seen again by orthopedics at $\mathrm{CHOP}$ at 11 years of age. At that time, he was unable to walk independently and was noted to have

Table 1 Clinical course for Patients 1, 2, and 3 with MPS IVA

\begin{tabular}{|c|c|c|c|}
\hline & Patient 1 & Patient 2 & Patient 3 \\
\hline Current age & 17 years, 8 months & 13 years, 1 month & 6 years, 2 months \\
\hline Type of genetic analysis & Whole-exome sequencing & Whole-exome sequencing & Targeted GALNS sequencing \\
\hline \multirow[t]{2}{*}{ Results of GALNS gene analysis } & \multicolumn{3}{|c|}{ c. 964G > C, p. A322P (paternally inherited, novel missense, variant of unknown significance) } \\
\hline & \multicolumn{3}{|c|}{ c. $611 \mathrm{~A}>$ G, p. N204S (maternally inherited, novel missense, variant of unknown significance) } \\
\hline Age at onset of symptoms & 5 years & 5 years & 3 years \\
\hline Age at diagnosis & 14 years, 7 months & 10 years & 3 years, 1 month \\
\hline Age at initiation of ERT & 14 years, 8 months & 10 years, 1 month & 3 years, 2 months \\
\hline
\end{tabular}

ERT enzyme replacement therapy, MPS IVA mucopolysaccharidosis type IVA 


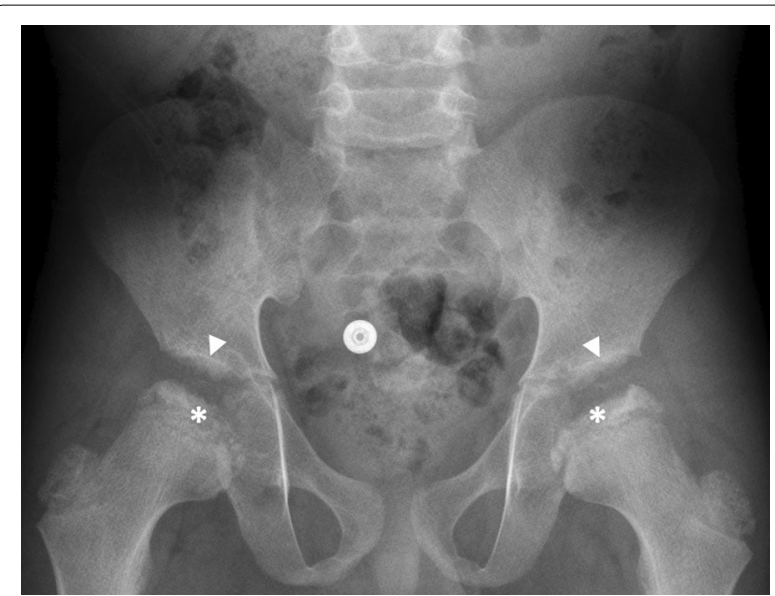

Fig. 1 Anteroposterior radiograph of hips and pelvis in Patient 1 at 6 years of age shows bilateral sclerotic, fragmented, and flattened proximal femoral epiphyses (asterisks), irregular acetabula (arrowheads), and coxa valga deformities. The patient was initially diagnosed with Legg-Calve-Perthes disease; in retrospect, acetabular irregularities and coxa valga would not be typical in this condition

a wide-based stance with increased weakness. Pelvis radiographs over time demonstrated progressive destructive change of the hips (Fig. 2). His progressive weakness prompted a referral to the neuromuscular clinic, and electromyography findings were suggestive of mild myopathy. Radiographs and MRIs of the spine revealed multiple abnormalities, with prominent middle third spine vertebral involvement, consisting of prominent anterior beaking, posterior endplate concavities, and mild platyspondyly (Fig. 3). Spondyloepiphyseal dysplasia was suspected due to the combination of proximal femoral epiphyseal abnormalities, odontoid hypoplasia (Fig. 4), and platyspondyly, but genetic sequencing and deletion/duplication studies of COL $2 A 1$ (collagen type II alpha 1) and $S E D L$ (spondyloepiphyseal dysplasia tarda) were negative. In retrospect, other radiographic features, including anterior vertebral beaking and metacarpal abnormalities (Fig. 5), favored MPS IVA. At 5 years of age, Patient 2 (middle sibling) was noted to experience the same pattern of clinical signs and symptoms as Patient 1. A skeletal survey was completed, which showed symmetrically abnormal femoral heads, radial and ulnar epiphyses, and carpal bones. Additionally, the lumbar vertebrae were noted to be slightly flattened and bullet shaped. Following diagnosis of the two older brothers, Patient 3 (youngest sibling) was diagnosed through family screening. The parents observed his wide-based gait at around 2.5 years of age, but the symptom was not brought to medical attention until diagnosis of his older siblings.

Patients 1 and 2 were referred for whole-exome sequencing at 14 and 9 years of age, respectively, which revealed compound heterozygous variants in the GALNS gene (Table 1). Enzyme testing revealed low GALNS activity. Urine GAG quantification revealed elevated GAGs, specifically chondroitin sulfate and keratan sulfate. Targeted-gene sequencing confirmed the diagnosis in Patient 3. Patient 3 was the least severely affected, with subtle differences in his skeletal survey and presenting with a slightly abnormal gait. The numerous skeletal abnormalities noted radiographically and reduced walking ability of Patient 1 highlight the progression of disease (Fig. 6).

The three siblings were started on intravenous infusions of elosulfase alfa at a dose of $2.0 \mathrm{mg} / \mathrm{kg} /$ week. The progression of clinical signs, symptoms, and laboratory studies in response to ERT after 30 months are summarized in Table 2 .

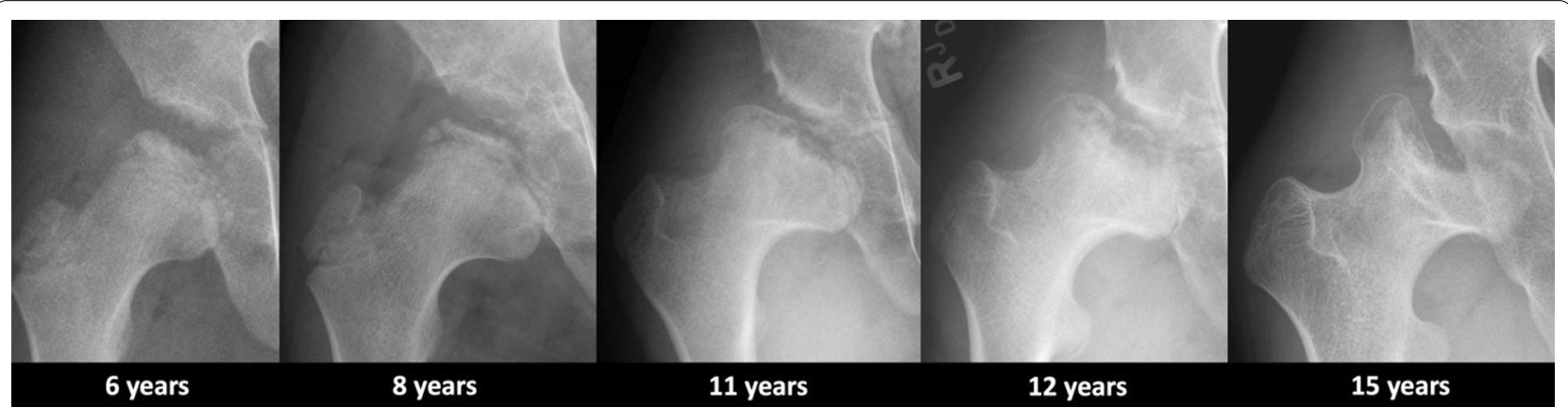

Fig. 2 Representative serial radiographs of the proximal right femur of Patient 1 over time show progressive flattening of the epiphysis, concomitant widening of the proximal metaphyses, and increased irregularity of the acetabula resulting in compensatory pseudarthrosis-like formation 

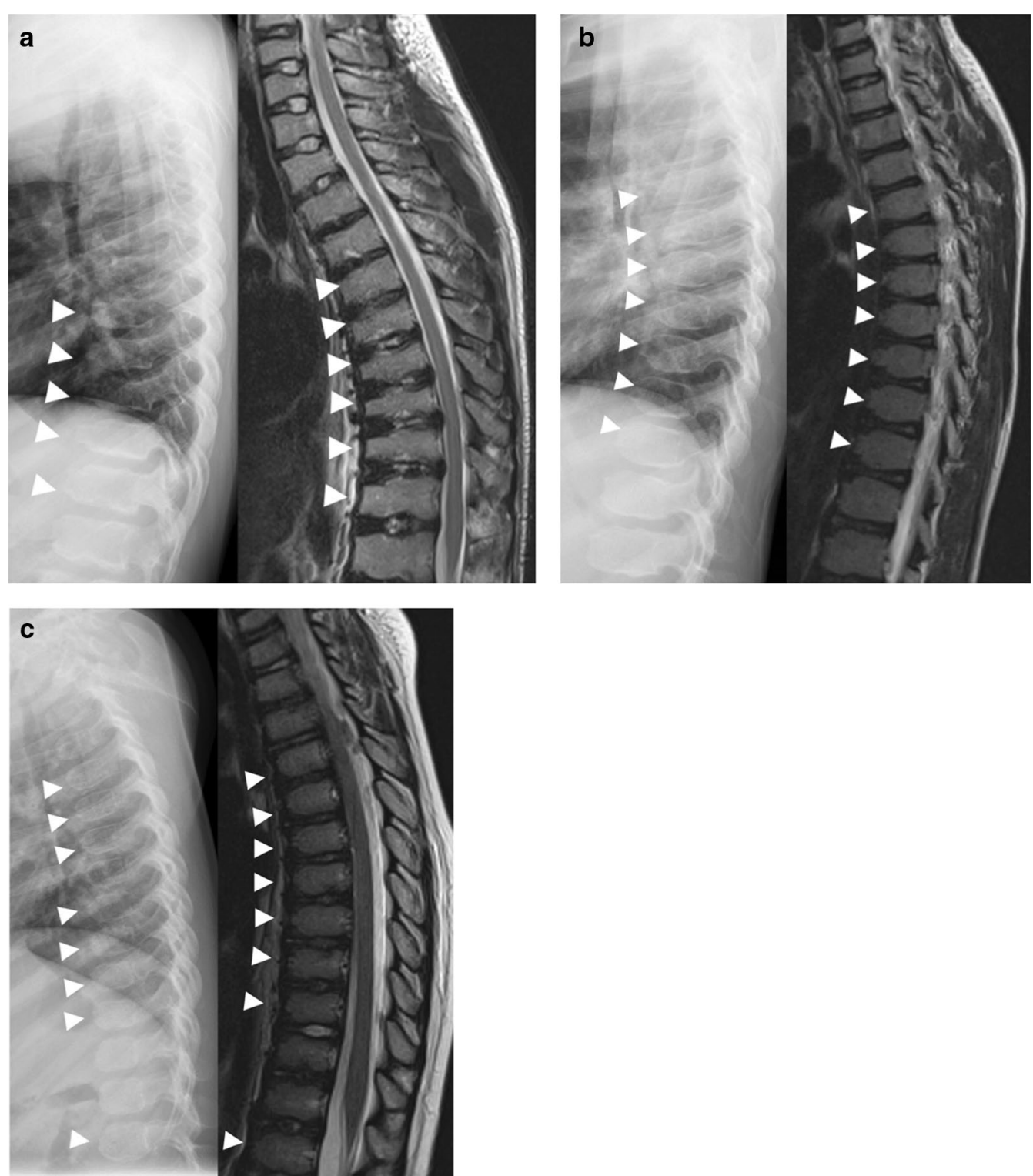

Fig. 3 Lateral radiographs and MRIs of the thoracic spine in the three siblings. a In Patient 1, lateral thoracic spine radiograph (left) at 10 years of age shows relatively moderate vertebral body height loss (platyspondyly) and anterior vertebral body beaking, most prominent in the mid-to-lower thoracic spine (arrowheads). Sagittal T2-weighted MRI of the thoracic spine (right) shows moderate platyspondyly with prominent anterior beaking of multiple thoracic and upper lumbar vertebral bodies (arrowheads). The patient was initially diagnosed with spondyloepiphyseal dysplasia on the basis of clinical presentation, platyspondyly, and femoral epiphyseal abnormalities on imaging, although anterior beaking in the middle third of the spine is highly suggestive of MPS IVA, and vertebral flattening is not as prominent as would be expected in spondyloepiphyseal dysplasia. $\mathbf{b}$ In Patient 2, lateral thoracic spine radiograph at 6 years of age (left) shows anterior beaking of multiple thoracic vertebral bodies (arrowheads). Sagittal T2-weighted MRI of the thoracic spine at 10 years of age (right) shows anterior vertebral body beaking (arrowheads) with mild vertebral height loss without platyspondyly. Presence of anterior vertebral body beaking in this case is strongly suggestive of MPS IVA. c In Patient 3, lateral thoracic spine radiograph at 3 years of age (left) shows anterior beaking of multiple thoracic vertebral bodies without significant vertebral body height loss. Sagittal T2-weighted MRI of the thoracic spine at 5 years of age (right) highlights anterior vertebral body beaking. As with this patient's siblings, anterior vertebral body beaking supported the diagnosis of MPS IVA

\section{Endurance}

After undergoing 30 months of ERT, all three patients showed an improvement in endurance, as measured by the 6-min walk test (6MWT). After 5 months of treatment, Patient 1 was unable to walk without the use of a walking aid and was only able to walk $50 \mathrm{~m}$ with the use 


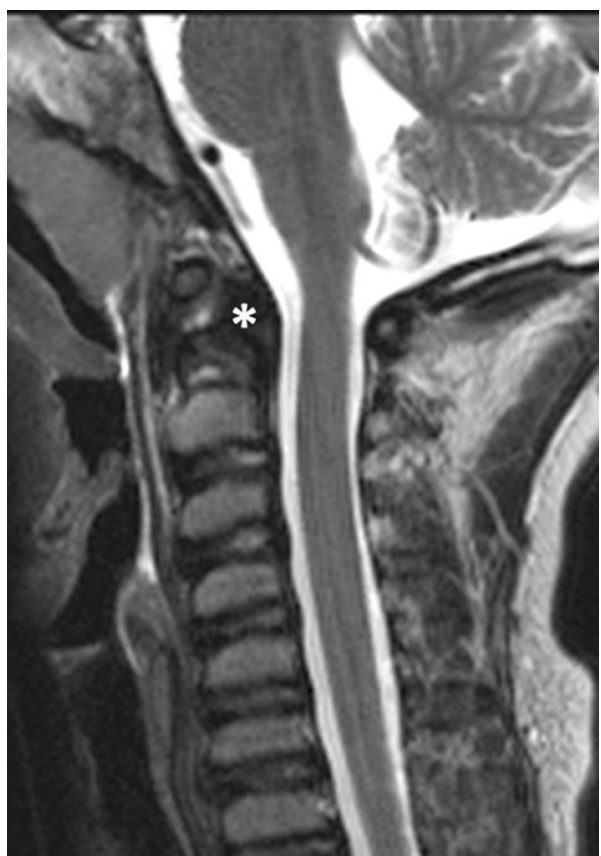

Fig. 4 Sagittal T2-weighted TSE MRI of the cervical spine of Patient 1 at 10 years of age shows dysplastic odontoid process of $C 2$, with irregular sclerosis and posterior migration of the tip of the dens (asterisk)

of bilateral forearm crutches during the 6MWT. However, after 30 months of ERT, Patient 1 was able to walk unassisted for $300 \mathrm{~m}$. The 6MWT results of Patients 2 and 3 were $265 \mathrm{~m}$ and $175 \mathrm{~m}$, respectively, after 5 months of ERT. The 6MWT distances increased to $425 \mathrm{~m}$ after 30 months for Patient 2 and 290 m after 15 months for Patient 3.

\section{Clinical measures of skeletal growth and function}

The height, weight, and BMI of all three patients increased from baseline after 30 months of ERT; of note, the largest increase in percentiles for both weight and height was found in Patient 3 (Table 2). Patient 1's height was $165.3 \mathrm{~cm}$ (7th percentile), and his weight was $65.3 \mathrm{~kg}$ (51st percentile) 30 months after starting ERT. After starting ERT, he gained weight (from the 39th percentile to the 51st percentile), and his BMI increased (from 48th percentile to the 78th percentile). Although he gained $4 \mathrm{~cm}$, his height percentile was not preserved, decreasing from the 25th to the 7th percentile. Patient 2's height, weight, and BMI were preserved, with his height being $151.5 \mathrm{~cm}$ (43rd percentile), weight being $37.1 \mathrm{~kg}$ (20th percentile), and BMI being $15.8 \mathrm{~kg} / \mathrm{cm}^{2}$ (11th percentile) at 30 months post-treatment. Patient 3's height was $116.4 \mathrm{~cm}$ (74th percentile), his weight was $27.3 \mathrm{~kg}$ (98th percentile), and his BMI was $19.9 \mathrm{~kg} / \mathrm{cm}^{2}$ (99th percentile) at 30 months post-treatment. The height percentile of Patient 3 increased from the 60th to the 74th percentile, his weight increased from the 87 th to the 98 th percentile, and his BMI increased from the 91st to the 99th percentile.

Joint range of motion (ROM) was assessed in the hips, knees, and ankles. Patient 1 experienced
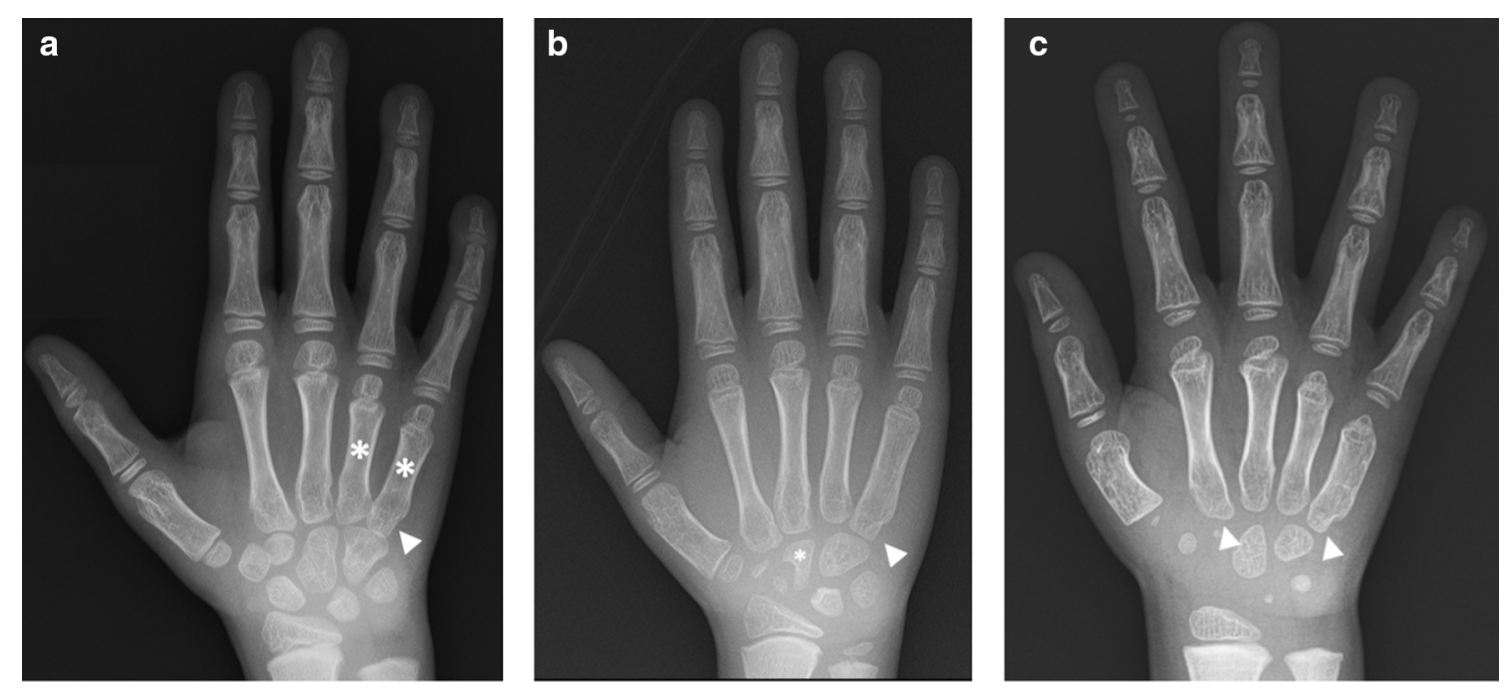

Fig. 5 Radiographic features of the hand in the three siblings supportive of MPS IVA. a Patient 1 at 6 years of age showed prominent shortening of the fourth and fifth metacarpals (asterisks) with proximal pointing of the fifth metacarpal (arrowhead) and widening of the first metacarpal. $\mathbf{b}$ Patient 2 at 6 years of age showed proximal pointing of the fifth metacarpal (arrowhead) and irregular carpal bones (asterisk). Notably, this patient's metacarpal abnormalities were much less conspicuous compared with those of his older brother (Patient 1) at the same age. c Patient 3 at 3 years of age showed proximally shortened, widened metacarpals with proximal pointing of the second and fifth metacarpals (arrowheads) 


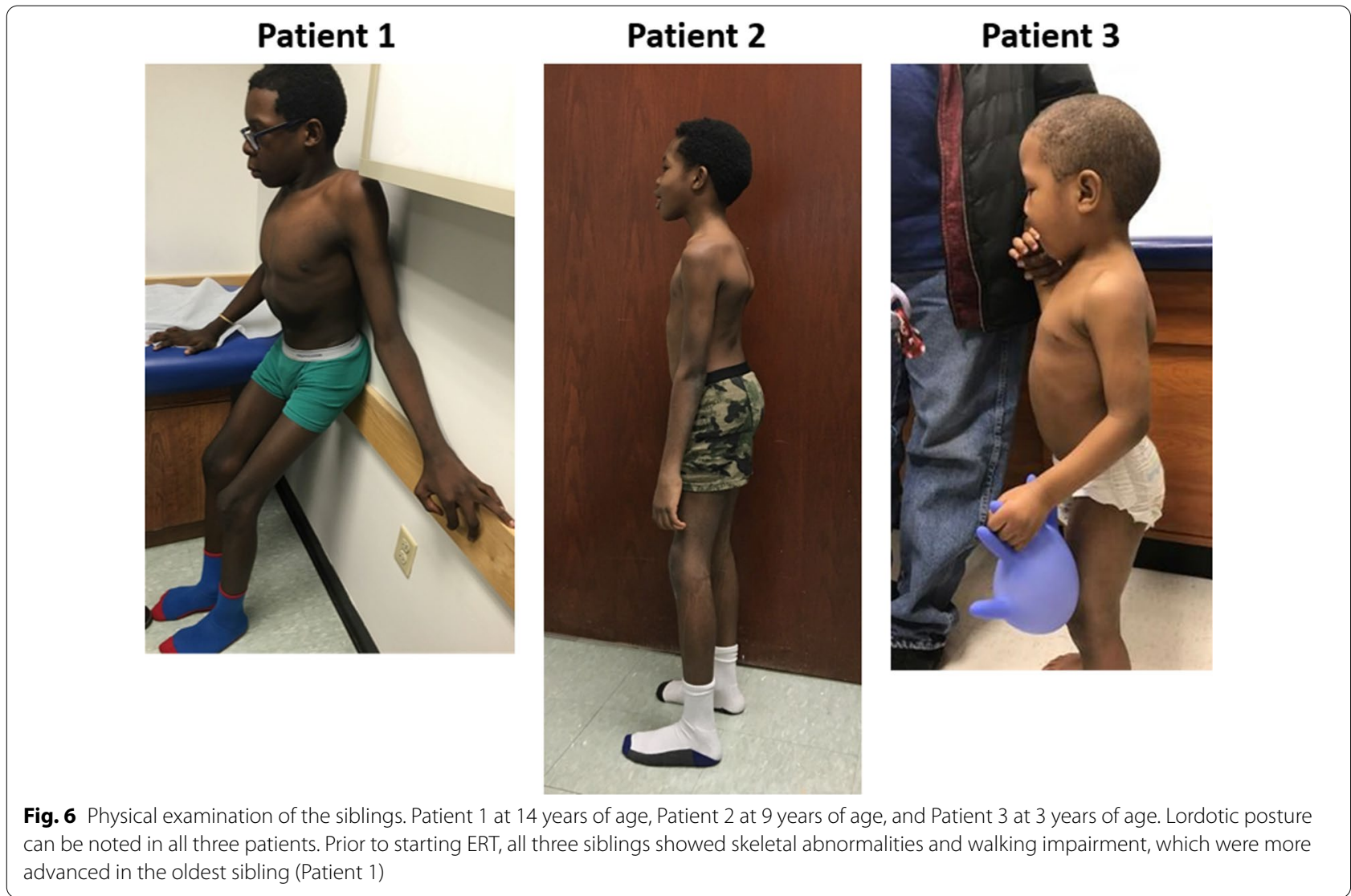

improvement $\left(>5^{\circ}\right)$ in bilateral hip abduction, left hip internal rotation, bilateral knee extension, and bilateral ankle dorsiflexion with the knee flexed after 5-30 months of ERT; right hip internal rotation remained unchanged. In Patient 2, similar improvements were seen in left hip internal and external rotation, left ankle dorsiflexion with knee extended, and bilateral popliteal angles after 5-30 months of ERT. Improvements to right ankle dorsiflexion with knee extended were minor $\left(<5^{\circ}\right)$, and right hip rotation was reduced (from $20^{\circ}$ before ERT to $10^{\circ}$ after 30 months of ERT for internal rotation and from $30^{\circ}$ before ERT to $5^{\circ}$ after 30 months of ERT for external rotation). In Patient 3, bilateral ankle dorsiflexion with knee extended ROM and bilateral popliteal angles improved after 30 months of ERT.

Prior to initiation of ERT, Patient 1 was unable to walk independently and unable to remain in standing position. Improvement in mobility was observed after 30 months of ERT, with the patient being able to walk without assistance for $300 \mathrm{~m}$. Additional files 1 and 2 demonstrates this improvement in mobility.

\section{Cardiopulmonary evaluation}

Initial cardiac evaluation was performed using an echocardiogram. There were no valve abnormalities or structural defects identified, and both left and right ventricles were of normal size with normal systolic shortening for all three patients before the initiation of ERT. There were no changes in their echocardiography findings or cardiac evaluations after 20 months of ERT.

Pulmonary function was evaluated using spirometry, and results were available for Patients 1 and 2. Prior to ERT, Patient 1 demonstrated $150 \%$ and $121 \%$ of predicted value for forced vital capacity (FVC) and forced expiratory volume in $1 \mathrm{~s}$ (FEV1), respectively. After 20 months of ERT, he had $157 \%$ and $121 \%$ of predicted value for FVC and FEV1, respectively. Patient 1's FEV1/FEV was moderately increased and forced expiratory flow between 25 and $75 \%$ of FVC $\left(\mathrm{FEF}_{25-75}\right)$ mildly decreased. Prior to ERT, Patient 2 had $71 \%$ of predicted value for both FVC and FEV1. After 20 months of ERT, his FVC and FEV1 predicted values increased to $85 \%$ and $78 \%$, respectively. His FEV1/FEV was moderately decreased and $\mathrm{FEF}_{25-75}$ was mildly increased. Patient 2 reported experiencing 
Table 2 Comparison of clinical signs, symptoms, and laboratory studies of the three siblings at baseline and after 30 months of ERT

\begin{tabular}{|c|c|c|c|c|c|c|}
\hline & \multicolumn{2}{|l|}{ Patient 1} & \multicolumn{2}{|l|}{ Patient 2} & \multicolumn{2}{|l|}{ Patient 3} \\
\hline & Before ERT & After ERT & Before ERT & After ERT & Before ERT & After ERT \\
\hline $6 \mathrm{MWD}^{\mathrm{a}} \mathrm{m}$ & $50^{d}$ & 300 & 265 & 425 & $175^{f}$ & $290^{e}$ \\
\hline $\begin{array}{l}\text { Height, cm } \\
\quad \text { (percentile }^{b} \text { ) }\end{array}$ & $161.4(25)$ & $165.3(7)$ & $137.5(44)$ & $153.1(43)$ & $97.0(60)$ & $117.2(74)$ \\
\hline $\begin{array}{l}\text { Weight, kg } \\
\left.\quad \text { (percentile }^{b}\right)\end{array}$ & $50.8(39)$ & $65.3(51)$ & $27.9(21)$ & $37.1(20)$ & $16.6(87)$ & $27.3(98)$ \\
\hline $\begin{array}{l}\mathrm{BMI}, \mathrm{kg} / \mathrm{cm}^{2} \\
\quad(\text { percentile }\end{array}$ & $19.5(48)$ & $23.9(78)$ & $14.8(11)$ & $15.8(11)$ & $17.6(91)$ & 19.9 (99) \\
\hline \multicolumn{7}{|l|}{ Joint $\mathrm{ROM}^{\mathrm{a}}{ }^{\mathrm{a}}$ degrees } \\
\hline \multirow[t]{2}{*}{ Hip abduction } & $\mathrm{R}: 10$ & $\mathrm{R}: 20^{\mathrm{e}}$ & $\mathrm{R}: 20$ & - & - & R: 55 \\
\hline & $\mathrm{L}: 15$ & $\mathrm{~L}: 20^{\mathrm{e}}$ & $\mathrm{L}: 20$ & & & $\mathrm{~L}: 55$ \\
\hline \multirow{2}{*}{$\begin{array}{l}\text { Hip internal rota- } \\
\text { tion }\end{array}$} & $\mathrm{R}: 10$ & $\mathrm{R}: 10^{\mathrm{e}}$ & $R: 30$ & $\mathrm{R}: 40^{\mathrm{e}}$ & - & $R: 60$ \\
\hline & $\mathrm{L}: 5$ & $\mathrm{~L}: 15^{\mathrm{e}}$ & $\mathrm{L}: 30$ & $\mathrm{~L}: 10^{\mathrm{e}}$ & & $\mathrm{L}: 60$ \\
\hline \multirow[t]{2}{*}{ Knee extension } & $\mathrm{R}:-35$ & $\mathrm{R}:-20$ & - & $R: 0$ & - & $\mathrm{R}: 0$ \\
\hline & $\mathrm{L}:-55$ & $\mathrm{~L}:-30$ & & $\mathrm{~L}:-15$ & & $\mathrm{~L}: 0$ \\
\hline \multirow{2}{*}{$\begin{array}{l}\text { Ankle dorsiflexion } \\
\text { with knee flexed }\end{array}$} & $R: 8$ & $\mathrm{R}: 15^{\mathrm{e}}$ & - & - & - & - \\
\hline & $\mathrm{L}: 10$ & $L: 15^{e}$ & & & & \\
\hline \multirow{2}{*}{$\begin{array}{l}\text { Ankle dorsiflex- } \\
\text { ion with knee } \\
\text { extended }\end{array}$} & - & $R: 0$ & $\mathrm{R}: 8$ & $\mathrm{R}: 10$ & $\mathrm{R}: 10$ & $\mathrm{R}: 15$ \\
\hline & & $\mathrm{L}: 5$ & L: 5 & $\mathrm{~L}: 10$ & $\mathrm{~L}: 10$ & $\mathrm{~L}: 15$ \\
\hline \multirow[t]{2}{*}{ Popliteal angle } & - & - & $\mathrm{R}: 15$ & $R: 25$ & $R: 30$ & $\mathrm{R}: 0$ \\
\hline & & & $\mathrm{L}: 15$ & $\mathrm{~L}: 35$ & $\mathrm{~L}: 30$ & $\mathrm{~L}: 0$ \\
\hline Cardiac function ${ }^{c}$ & $\begin{array}{l}\text { No significant } \\
\text { findings }\end{array}$ & - & $\begin{array}{l}\text { No significant } \\
\text { findings }\end{array}$ & $\begin{array}{l}\text { No significant } \\
\text { changes }\end{array}$ & $\begin{array}{l}\text { No significant } \\
\text { findings }\end{array}$ & - \\
\hline \multicolumn{7}{|l|}{ Respiratory function } \\
\hline $\mathrm{FVC},{ }^{\mathrm{C}} \%$ & 150 & 157 & 71 & 85 & - & - \\
\hline FEV1,,$\%$ & 121 & 121 & 71 & 78 & - & - \\
\hline FEV1/FVC & 71 & 79 & 101 & 81 & - & - \\
\hline $\mathrm{FEF}_{25-75}{ }^{\mathrm{C}} \%$ & 76 & 70 & 41 & 46 & - & - \\
\hline Polysomnography & - & $\begin{array}{l}\text { Snoring, no } \\
\text { evidence of } \\
\text { significant OSA }\end{array}$ & $\begin{array}{l}\text { No evidence of } \\
\text { OSA or restrictive } \\
\text { lung disease }\end{array}$ & Normal breathing & $\begin{array}{l}\text { No evidence of } \\
\text { OSA or restrictive } \\
\text { lung disease }\end{array}$ & $\begin{array}{c}\text { Snoring, no evidence } \\
\text { of substantial OSA }\end{array}$ \\
\hline Ophthalmology & Mild corneal haze & Mild corneal haze & Mild corneal haze & Mild corneal haze & Subtle corneal haze & $\begin{array}{l}\text { Diffuse fine corneal } \\
\text { haze }\end{array}$ \\
\hline \multicolumn{7}{|l|}{ Urinary GAGs } \\
\hline $\begin{array}{l}\text { Chondroitin } \\
\text { sulfate, } \mathrm{g} / \mathrm{mol} \\
\text { creatinine }\end{array}$ & 7.77 & $2.87^{e}$ & 9.61 & $8.01^{\mathrm{e}}$ & 21.2 & $14.19^{e}$ \\
\hline $\begin{array}{l}\text { Keratan sulfate, } \\
\mu \mathrm{g} / \mathrm{mol} \text { creati- } \\
\text { nine }\end{array}$ & 5.35 & $2.97^{e}$ & 7.21 & $6.33^{e}$ & 16.6 & $9.95^{e}$ \\
\hline
\end{tabular}

6MWD 6-min walk distance, $B M I$ body mass index, $C D C$ US Centers for Disease Control and Prevention, $E R T$ enzyme replacement therapy, $F E F_{25-75}$ forced expiratory flow between 25 and $75 \%$ of FVC, FEV1 forced expiratory volume in $1 \mathrm{~s}, F V C$ forced vital capacity, GAG glycosaminoglycan, OSA obstructive sleep apnea, ROM range of motion

a Initial joint ROM and 6MWD evaluations were conducted after initiation of treatment (Patients 1 and 2, 5 months; Patient 3, 3 months)

b CDC Clinical Growth Charts for 2-20 years of age

c Evaluation after 20 months of ERT

d Ambulation with bilateral forearm crutches in $59 \mathrm{~s}$

e Evaluation after 30 months of ERT

f Distance walked in 2.75 min due to refusal to continue 
shortness of breath during activity and excessive daytime somnolence when evaluated after 15 months of ERT. At 20 months of ERT, polysomnography showed snoring with no evidence of significant obstructive sleep apnea in Patients 1 and 3. Patient 2 had normal breathing during sleep.

\section{Ophthalmology}

Both Patient 1 and Patient 2 had bilateral mild corneal haze prior to ERT, which remained unchanged after 30 months of ERT. In Patient 3, bilateral subtle corneal haze improved to diffuse, fine corneal haze after 30 months of ERT.

\section{Urinary glycosaminoglycan levels}

In all three patients, urinary chondroitin sulfate (g/ mol creatinine) and keratan sulfate ( $\mu \mathrm{g} / \mathrm{mol}$ creatinine) decreased with ERT (Table 2).

\section{ERT dosage and adverse reactions}

All three patients received weekly infusions of elosulfase alfa at a dose of $2.0 \mathrm{mg} / \mathrm{kg}$, and treatment was well tolerated throughout its duration without any adverse events.

\section{Clinical course of the three patients with MPS IVA}

Patients with MPS IVA usually present with clinical signs or symptoms at the end of the first year of life. Most who present with classical symptoms are diagnosed at 2-3 years of age due to disproportional short stature, waddling gait, pectus carinatum, and frequent respiratory infections.

Diagnostic delay: Patient 1 presented with limp and hip pain around 5 years of age. He was seen by orthopedics at an outside institution and diagnosed with bilateral Legg-Calve-Perthes disease of unknown etiology. $\mathrm{He}$ was referred to orthopedics at the CHOP at 7 years of age, where a work-up for Legg-Calve-Perthes disease was undertaken and tested negative, including normal alpha globin, prothrombin, and Factor V Leiden genetic testing. His orthopedic surgeon questioned the diagnosis and referral to neuromuscular was recommended, given the progression of his symptoms and weakness. However, due to insurance issues, a consultation was not completed, and the patient was lost to follow-up for several years. He re-presented to care when his younger brother (Patient 2) developed the same symptoms. Further evaluation of the case by a neurologist and clinical geneticist lead to sending for whole-exome sequencing, which revealed compound heterozygous variants in the GALNS gene. In this case, the protracted diagnostic odyssey was likely due to the initial subtlety of findings and lack of knowledge about symptoms and signs of this rare, inherited metabolic disease among many physicians. Typically, disproportionately short stature has been considered a hallmark of this disorder. In this case series, Patients 1 and 2 were initially of normal height. Thus, a high index of suspicion and diligent examination of radiographs is required.

Treatment response: Patient 1 was severely affected at the time of diagnosis. He was unable to stand up without assistance and only capable of taking a few steps with assistance. After starting ERT, his endurance improved, and he was able to stand up independently; after 6 months of therapy, he started walking with crutches. One year after starting ERT, he started walking unassisted. Video 1 highlights his ability to walk unassisted during the 6MWT. His 6MWD increased significantly. His urine GAGs decreased, and his cardiac, pulmonary, and ophthalmological findings were stable. Due to the late diagnosis and severe skeletal involvement, his height increased only 4 inches in 30 months on ERT.

Patient 2 presented with a wide-based gait and hip pain at around 5 years of age. His symptoms remained more or less stable for the next 4 years, although each year, he had increased difficulty with walking. When he was diagnosed at 9 years of age, his 6MWD was $265 \mathrm{~m}$, which increased to $425 \mathrm{~m}$ after 30 months of ERT. His walk is shown in Video 2. His height remained preserved around the 40th percentile.

Patient 3 was 3 years old at the time of diagnosis through family screening. Parents recalled that they noticed a wide-based gait beginning at around 2.5 years of age but were not concerned until his older brothers were diagnosed with MPS IVA. His waddling gait remained stable after the ERT. His 6MWD increased from 175 to $290 \mathrm{~m}$, but the accuracy of this measurement was compromised because of poor cooperation. His height increased from the 60th to the 74th percentile.

\section{Discussion}

The efficacy and safety of elosulfase alfa in treating MPS IVA have previously been demonstrated in patients $\geq 5$ years and $<5$ years of age. In this report, three siblings with MPS IVA initiated weekly infusions of elosulfase alfa starting at 14.7, 10.1, and 3.2 years of age, respectively. Thirty months of ERT was well tolerated and led to improvements in endurance (6MWD), growth, and joint ROM, and reduction in urinary GAGs, consistent with prior clinical studies.

Early diagnosis of MPS IVA is important to initiate treatment with ERT as soon as possible, as skeletal manifestations are considered irreversible. In this report, the three siblings received ERT at different stages of MPS IVA; Patient 1 had the most-severe presentation and was unable to walk independently at the start of treatment, whereas Patients 2 and 3 have developed some 
radiographic features of MPS IVA but have not yet experienced severe impairment to their mobility. While all three patients experienced improvement in clinical outcomes after 30 months of ERT, Patient 1 showed remarkable improvement in being able to walk unassisted, albeit not to the same level of his siblings who initiated treatment earlier. These three cases show us that ERT can reverse some progressive symptoms while slowing others.

The clinical presentation of MPS IVA is heterogeneous, and initial findings are subtle. This makes the diagnosis a challenge and can lead to substantial delays, as underscored by the diagnostic journey of Patient $1[1,8]$. This case series highlights the importance of early recognition of the clinical and imaging findings of MPS IVA, especially considering the progressive nature of this disorder. The characteristic, progressive radiographic features in the pelvis, spine, and hand, as documented in this study, are key for MPS IVA diagnosis and follow-up testing. Thus, when evaluating patients with skeletal anomalies, imaging multiple body regions is recommended. With findings such as anterior beaking of vertebrae or bilateral femoral head dysplasia, MPS IVA should be included in the differential, as early treatment can reduce morbidity.

Despite the three siblings initially presenting with similar signs and symptoms, Patient 1 had a more-severe functional disability due to 9-year diagnostic delay. Improving awareness and recognition of MPS IVA will enable earlier diagnosis and treatment [8]. Evidence- and consensus-based management guidelines for MPS IVA for healthcare professionals have recommended implementation of newborn screening for MPS IVA to allow very early ERT to help slow the progression of the disease and improve outcomes [1]. Long-term ERT (elosulfase alfa, $2.0 \mathrm{mg} / \mathrm{kg}$ weekly IV infusions) is recommended in all patients with a confirmed MPS IVA diagnosis [1].

\section{Conclusion}

Treatment with elosulfase alfa ERT in three siblings with MPS IVA was effective in improving clinical outcomes and was well tolerated. The variable clinical presentation, delay in diagnosis, and progressive nature of MPS IVA, as demonstrated by these three siblings, highlight the importance of improving awareness and recognition of the disease's early signs and symptoms. The initiation of ERT in these siblings improved their endurance, reduced their pain, and improved their ranges of motion. In the younger siblings, height was preserved or improved. Additionally, in the youngest sibling, ophthalmologic findings improved. The youngest and middle siblings continue to walk independently, and the oldest sibling can now walk with crutches or unassisted for $300 \mathrm{~m}$. This highlights the substantial effect of ERT in slowing disease progression and improving patient outcomes even in the late-diagnosed patient. Newborn screening for MPS IVA is necessary to prevent diagnostic delay and initiate treatment as early as possible to achieve better clinical outcomes.

\section{Supplementary information}

Supplementary information accompanies this paper at https://doi. org/10.1186/s13023-020-01618-y.

Additional file 1: The patient 1's 6 minute-walk test at 17 year 8 months of age on ERT.

Additional file 2: The patient 2's 6 minute-walk test at age 13 year 1 month on ERT.

\section{Abbreviations}

6MWD: 6-Min walk distance; 6MWT: 6-Min walk test; BMI: Body mass index; CHOP: Children's Hospital of Philadelphia; COL2A1: Collagen type II alpha 1; ERT: Enzyme replacement therapy; $\mathrm{FEF}_{25-75}$ : Forced expiratory flow between 25 and $75 \%$ of FVC; FEV1: Forced expiratory volume in $1 \mathrm{~s}$; FVC: Forced vital capacity; GAGs: Glycosaminoglycans; GALNS: N-Acetylgalactosamine-6-sulfatase; MPS: Mucopolysaccharidosis; MRI: Magnetic resonance imaging; ROM: Range of motion; SEDL: Spondyloepiphyseal dysplasia tarda.

\section{Acknowledgements}

We would like to express our gratitude to the patients and their family. We also thank Nelson Jen, PhD (Chameleon Communications International) for editorial assistance in the preparation of this manuscript.

\section{Authors' contributions}

All authors have reviewed and approved this manuscript. CF evaluated the patients and wrote the manuscript. DM evaluated the patients, reviewed and edited the manuscript. NL, CM, and TK evaluated the patients, reviewed and edited the manuscript. AD read the images, reviewed and edited the manuscript. All authors read and approved the final manuscript.

\section{Funding}

Open access and basic editorial assistance funding were provided by BioMarin Pharmaceutical Inc. BioMarin Pharmaceutical Inc. was not involved in the acquisition, analysis, interpretation of data, or in the content development of the manuscript.

Availability of data and materials

All data generated or analyzed during this study are included in this published article (and its Additional files 1 and 2).

Ethics approval and consent to participate

Parental consent was obtained to use the patients' medical data, photographs, and videos.

\section{Consent for publication}

Parental consent was obtained to publish the patient's medical data, photographs, and videos.

\section{Competing interests}

Can Ficicioglu, MD, PhD, has served as an advisor or consultant for: Genzyme, Horizon, Orphan Tech., Recordati, Shire, and Sobi. He received grants for clinical research from: Genzyme, Orphan Tec, RegenxBio, Takeda, and Vtesse. Dena R. Matalon, MD, none. Nicole Luongo, PA-C, none. Caitlin Menello, CGC, none. Tracy Kornafel, none. Andrew J. Degnan, MD, none.

\section{Author details}

${ }^{1}$ Division of Human Genetics/Metabolism, Lysosomal Storage Diseases Program, The Children's Hospital of Philadelphia, Perelman School of Medicine, The University of Pennsylvania, 3401 Civic Center Blvd., Philadelphia, PA 19104, 
USA. ${ }^{2}$ Stanford University, Lucile Packard Children's Hospital, Palo Alto, CA, USA. ${ }^{3}$ Abington Hospital - Jefferson Health, Abington, PA, USA.

Received: 26 August 2020 Accepted: 16 November 2020

Published online: 30 November 2020

\section{References}

1. Akyol MU, Alden TD, Amartino H, Ashworth J, Belani K, Berger KI, Borgo A, Braunlin E, Eto Y, Gold Jl. Recommendations for the management of MPS IVA: systematic evidence-and consensus-based guidance. Orphanet J Rare Dis. 2019:14(1):137.

2. Tomatsu S, Yasuda E, Patel P, Ruhnke K, Shimada T, Mackenzie WG, Mason R, Thacker MM, Theroux M, Montaño AM. Morquio A syndrome: diagnosis and current and future therapies. Pediatr Endocrinol Rev. 2014;12(1):141.

3. Yasuda E, Fushimi K, Suzuki Y, Shimizu K, Takami T, Zustin J, Patel P, Ruhnke K, Shimada T, Boyce B. Pathogenesis of Morquio A syndrome: an autopsied case reveals systemic storage disorder. Mol Genet Metab. 2013;109(3):301-11.

4. Matalon R, Arbogast B, Dorfman A. Deficiency of chondroitin sulfate $\mathrm{N}$-acetylgalactosamine 4-sulfate sulfatase in Maroteaux-Lamy syndrome. Biochem Biophys Res Commun. 1974;61(4):1450-7.

5. Muenzer J. Overview of the mucopolysaccharidoses. Rheumatology. 2011;50(suppl_5):v4-12.

6. Harmatz P, Mengel KE, Giugliani R, Valayannopoulos V, Lin SP, Parini R, Guffon N, Burton BK, Hendriksz CJ, Mitchell J, et al. The Morquio A Clinical Assessment Program: baseline results illustrating progressive, multisystemic clinical impairments in Morquio A subjects. Mol Genet Metab. 2013;109(1):54-61.

7. Hendriksz CJ, Al-Jawad M, Berger KI, Hawley SM, Lawrence R, Mc Ardle C, Summers CG, Wright E, Braunlin E. Clinical overview and treatment options for non-skeletal manifestations of mucopolysaccharidosis type IVA. J Inherit Metab Dis. 2013;36(2):309-22.

8. Wood TC, Harvey K, Beck M, Burin MG, Chien Y-H, Church HJ, D'Almeida V, van Diggelen OP, Fietz M, Giugliani R. Diagnosing mucopolysaccharidosis IVA. J Inherit Metab Dis. 2013:36(2):293-307.

9. BioMarin Pharmaceutical Inc. Vimizim ${ }^{\circledR}$ (elosulfase alfa) [prescribing information]; 2014

10. BioMarin Pharmaceutical Inc. Vimizim ${ }^{\circledR}$ (elosulfase alfa) [summary of product characteristics]; 2014

11. Hendriksz CJ, Burton B, Fleming TR, Harmatz P, Hughes D, Jones SA, Lin SP, Mengel E, Scarpa M, Valayannopoulos V, et al. Efficacy and safety of enzyme replacement therapy with BMN 110 (elosulfase alfa) for Morquio A syndrome (mucopolysaccharidosis IVA): a phase 3 randomised placebo-controlled study. J Inherit Metab Dis. 2014;37(6):979-90.

12. Jones SA, Bialer M, Parini R, Martin K, Wang H, Yang K, Shaywitz AJ, Harmatz P. Safety and clinical activity of elosulfase alfa in pediatric patients with Morquio A syndrome (mucopolysaccharidosis IVA) less than $5 \mathrm{y}$. Pediatr Res. 2015:78(6):717-22.

13. Furujo M, Kubo T, Kosuga M, Okuyama T. Enzyme replacement therapy attenuates disease progression in two Japanese siblings with mucopolysaccharidosis type VI. Mol Genet Metab. 2011;104(4):597-602.

14. Furujo M, Kosuga M, Okuyama T. Enzyme replacement therapy attenuates disease progression in two Japanese siblings with mucopolysaccharidosis type VI: 10-year follow up. Mol Genet Metab Rep. 2017;13:69-75.

15. Matalon DR, Dougherty P, Lulis L, Medne L, Krantz I, Yum S, Ficicioglu C. The diagnosis and natural history of mucopolysaccharidosis IVA in one family. Mol Genet Metab. 2018;2018:249-50.

\section{Publisher's Note}

Springer Nature remains neutral with regard to jurisdictional claims in published maps and institutional affiliations.
Ready to submit your research? Choose BMC and benefit from:

- fast, convenient online submission

- thorough peer review by experienced researchers in your field

- rapid publication on acceptance

- support for research data, including large and complex data types

- gold Open Access which fosters wider collaboration and increased citations

- maximum visibility for your research: over 100M website views per year

At $B M C$, research is always in progress.

Learn more biomedcentral.com/submissions 